\title{
Leadership Style And Organizational Culture In Learning Organization: A Comparative Study
}

Sapna Rijal, Purbanchal University, Nepal

\begin{abstract}
Scholars and practitioners have identified transformational leadership and organizational culture as important factors that influence the development of learning organization. Yet, few studies have empirically examined the impact of transformational leadership and organizational culture on learning organization. This study proposes hypotheses to understand the impact of transformational leadership and organizational culture on the development of learning organization. Data was collected from the pharmaceutical sector and a comparison was drawn between India and Nepal. Results indicate transformational leadership and organizational culture have a positive influence in the development of learning organization. The implication of the findings and possible directions for future research are discussed.
\end{abstract}

Keywords: Learning Organization, Transformational Leadership, Generative and Adaptive Organizational Culture, Pharmaceutical Sector, India and Nepal.

\section{INTRODUCTION}

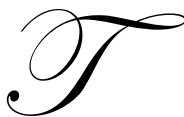

he concept of Learning Organization has received heightened attention from scholars and others in recent years. As per Jones and Hendry (1994) the term "Learning Organization" seems to have been coined around 1988 by Hayes et. al. in the USA and Pedlar et. al. in the UK but the origin of the word in the literature can be traced back to the 1920s. But the concept attracted much attention in the 1990's when Peter Senge (1994) popularized this concept in his landmark book "The Fifth Discipline."

In this era of competitive pressure, learning organization has gained popularity as the capacity for change and improvement is linked with learning and to obtain and sustain competitive advantage, organizations must enhance their learning capability and must be able to learn better and faster from their successes and failures, from within and from outside (Marquardt, 1996).

The extant literature has identified a number of factors that influence the development of learning organization. Fiol \& Lyles (1985) suggest that the organization culture, the strategy, organization structure and the environment in which the organization operates influence the development of learning organization. Caudron (1993), Schien (1993), Garvin (1993), Marquardt (1996) have identified the important role culture plays in creating a learning organization.

Senge (1994) has identified a different role for leaders of learning organization. Similarly, many authors have emphasized the important role leadership plays in the development of the learning organization (Johnson, 1998; Prewitt, 2003; Sadler, 2003). The concept of culture is also one of the major variable and essential ingredients in the development of a learning organization. Barrett (1995), Hershey et. al. (2000) suggest that a learning culture characterized by continuous learning from experience, experimentation, questioning and dialogue, is the only way to sustain a competitive advantage over the long term in an increasingly complex and turbulent environment. 
Against this background, this article aims to understand the leadership style and the cultural transformation required to facilitate the transition to a learning organization. The type of leadership considered in this study is "transformational leadership". Transformational leadership has been the subject of extensive research in the past decade but little research effort has been exerted to study the influence of transformational leadership in the development of learning organization. Much has been researched about organizational culture and change. However, much less effort has been expended in studying the cultural transformation required in organizations making the transition to a learning organization.

In view of the current state of literature, this article seeks to study the relationship between transformational leadership style and learning organization as well as the relationship between organizational culture and learning organization. It aims to identify the key variables that will predict the dimensions of learning organization based on transformational leadership and organizational culture dimensions. It also seeks to investigate the difference in the development of learning organization between India and Nepal. To address these issues the article first highlights the role of leadership and organizational culture and provides an overview of the relevant literature as the basis for specifying the hypotheses. Then the method of the study is discussed, followed by presentation and discussion of the findings. The final section provides a summary and discusses implications for future research.

\section{ROLE OF LEADERSHIP IN LEARNING ORGANIZATION}

The competitive pressures of the present environment necessitates the need to focus on risk-taking and creativity, therefore traditional management styles which insist on compliance and enforcement of rules are now considered inappropriate. In such a scenario, developing new competencies and capabilities has gained importance and this places learning at the center of organizations. This has led to the development of new organizational forms known as "Learning Organization" and these organizations are more adaptive and flexible and tap the learning of individuals to improve organizational performance and enhance organizational learning.

Learning organization hence requires a leader who brings out the best in the followers, leadership that is more adaptive and flexible. Senge identified three leadership roles that are important for building a learning organization. "Leaders as designers", "leaders as teachers", and the "leaders as stewards". Similarly, Marquardt (1996) identified six leadership roles in a learning organization. He considers the role of "instructor", "coach" and "mentor" as the most important aspect of leadership in learning organization. In the role of "knowledge managers", "colearners and model for learning", leaders are learners themselves. As "architect and designers" and "coordinator" they are responsible for creating a learning environment motivating followers to perform at their best. Johnson (2002) considers visioning, empowerment and leader's role in learning as crucial skills for leaders of learning organization.

\section{ROLE OF ORGANIZATIONAL CULTURE IN LEARNING ORGANIZATION}

At present times when the environment is highly competitive, where markets and products proliferate rapidly, a strong culture, which does not encourage innovation, proves to be a disadvantage to a firm. Organizations need to be flexible, adaptive and innovative to survive in this changing environment. The focus on flexibility, adaptability and innovation falls mainly within the domain of organizational culture, since organizational culture is integral to effective change initiatives and strategies (Bluedorn and Lundgren, 1993). The need for adaptive, flexible and innovative organizational culture within organizations in response to the turbulence and uncertainty in the organizational environment has long been suggested. Kotter and Heskett (1992) identified the adaptive culture as the 'optimal' organizational culture and stated "only cultures that can help organizations anticipate and adapt to environmental change will be associated with superior performance over long periods of time". Bass and Avolio (1993) also highlighted the importance of adaptive and flexible organizational culture and distinguish between transformational and transactional organizational culture. Transformational culture refers to those organizational cultures supportive of innovation, transformation and change and transactional cultures as those that maintain the status quo, are based on pre-established rules and structures, and inspire limited levels of commitment and motivation. 
Research evidence suggests significant positive correlations between transformational cultures and desirable organizational and individual outcomes (Parry and Proctor, 2000). An essential factor that adds value in transformational organizational culture is the degree to which it supports and promotes innovation and entrepreneurial activity. Within a rapidly changing and turbulent environment, innovation plays a crucial part in the long-term survival of an organization. In contrast, a "pure" transactional culture focuses on everything in terms of explicit and implicit contractual relationships' (Bass and Avolio, 1993). They state that, in this sort of culture, individualism is very strong and therefore a concern for self-interest, rather than organizational aims, dominates. Thus, commitment is often short-term, existing to the extent of rewards provided by the organization (Bass, 1998). Transactional cultures has been found to correlate significantly and negatively with organizational and leadership outcomes (Parry and Proctor, 2000).

\section{ROLE OF TRANSFORMATIONAL LEADERSHIP IN LEARNING ORGANIZATION}

Leadership takes on a different role in a learning organization. To achieve the vision of learning organization leadership capabilities must be developed. As identified by various authors' leaders in learning organization need to communicate a clear and compelling vision of the future organization to obtain commitment from the organizational members, encourage followers to respond to environmental uncertainty through creativity and innovativeness, change their mental models and encourage them to seek learning oriented behaviors and embrace continuous learning. These roles are suitable to a transformational leader as they are champions of technological innovation (Howell and Higgins, 1990), achieve successful transformation of an organization by aligning the organizational vision, organizational design and management practices (Appelbaum et. al., 1998), change long held assumptions, values and beliefs and encourage employees to learn new behaviors (LeBrasseur et. al., 2002). Transformational leader are change agents, who take the responsibility for revitalizing an organization. They define the need for change, create new visions, mobilize commitment to those visions and ultimately transform an organization.

The present day environmental pressure necessitates the transformation to a learning organization. Changing from a traditional organization to a learning organization aims to transform traditional organization into a more responsive and effective organization that is able to withstand and survive the environmental pressure and hence improve its performance in the face of the turbulent environment. Environmental uncertainties are stressful to followers, as they do not understand the direction of change, the potential impact of the change, and the success of a particular response. Under such conditions, the idealized vision articulated by the leader provides a challenge and motivating force for change to the followers as it represents a perspective shared by all the followers and promises to meet their hopes and aspirations (Conger and Kanungo, 1987; Waldman et. al., 2001). This age of rapid change, calls for a new kind of leadership to enable organizations to transform and cope with the changes (Tichy and Ulrich, 1984). This new brand of leaders must have the ability to help the organization develop a vision of what it can be, to mobilize the organization to accept and work towards achieving the new vision, and to institutionalize the changes that must last over time. These new leaders are called transformational leaders and learning organizations require the leadership of the transformational leader who enables the members to make sense of the environmental uncertainty by continuous learning through the mechanism of organizational learning. A transformational leader with a shared vision and effective communication can enable members to understand the goals and aspirations of the learning organization, the importance of organizational learning in the transformation process and thus change their mental models and encourage them to seek learning-oriented behaviors and embrace continuous learning.

On the basis of the above discussions the following hypothesis has been specified as the basis for focusing the empirical investigation:

Hypothesis 1: Transformational leadership has a significant and positive influence in building a learning organization. 


\section{ROLE OF ADAPTIVE AND GENERATIVE ORGANIZATIONAL CULTURE AND LEARNING ORGANIZATION}

To make the transition to a learning organization, organizations require a culture that supports and facilitates this transformation. Schien, (1996) considers three cultures to be present in every organization: the operator culture, the engineering culture and the executive culture. If an organization attempts to reinvent itself and learn in a generative way then there has to be proper alignment among these three cultures otherwise the learning initiatives will be short lived. Through "dialogue" organizations can achieve mutual understanding among the three cultures and promote the value of trust, openness and communication to enhance learning. Paton and McCalman (2000) also consider open dialogue, experimentation and risk-taking as prerequisites to a learning culture.

The challenge for organizations in this present environment is to create contexts in which members continually learn and experiment, are innovative and strive for the creation of new ideas and new products, as it is not sufficient for organizations to respond, adapt and cope with the pressures of change (Barrett, 1995). The lifeblood of a learning organization is a free and open system for communicating information and knowledge as it encourages knowledge creation and enhances learning (Hill, 1996). Experiments are catalyst for creating new knowledge and learning and organizational members should be encouraged to conduct experiments no matter what the outcome. McGill et. al. (1992) considers experimentation and risk taking as important values that promote a learning culture.

The prior literature provides the basis for expecting a relationship between organizational culture and learning organization and the following hypothesis has been specified as the basis for focusing the empirical investigation.

Hypothesis 2: A generative and adaptive culture will have a significant and positive relationship with the dimensions of a learning organization.

This study also seeks to investigate the difference in the development of learning organization between India and Nepal and the following hypothesis has been specified as the basis for focusing the empirical investigation.

Hypothesis 3: There will be no significant difference among the various dimensions of learning organization between India and Nepal.

The theoretical model depicting the framework for the study and the relationship among the hypothesis is shown in Figure 1.

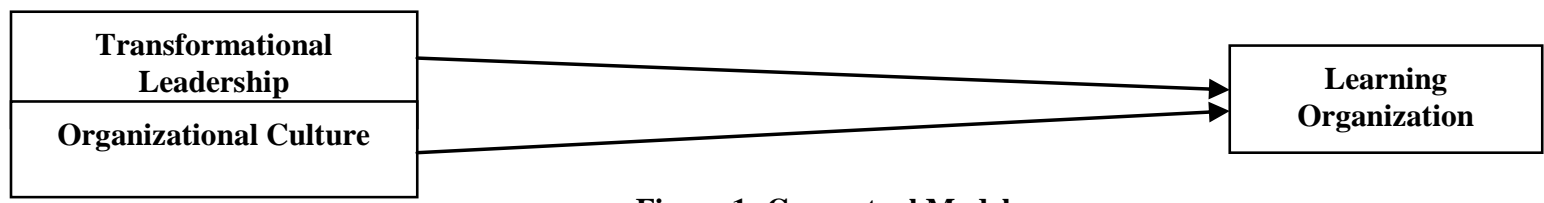

Figure 1: Conceptual Model

\section{METHOD}

\section{Sample and Procedures}

This is a comparative study designed to compare selected organizations in the pharmaceutical sector between Nepal and India. This industry was chosen for the study because improving organizational performance through learning has been a critical factor for company survival due to the industry's rapid technological advances and highly competitive markets. 
Four organizations each, from the pharmaceutical industry, were selected in both Nepal and India. Both countries are developing economies. In the past decade, India has advanced at an alarming rate and struggled to build and maintain sustainable competitive advantage in the present global scenario. Nepal is undergoing political and economic transformation and is opening up its economy to Foreign Direct Investment and Multi-nationals. Therefore, it was thought useful to compare selected companies in the two countries to see if there exist any differences in the development of learning organization and to explore how successful practices of one country could be utilized in the other countries.

Data was collected through a survey instrument and the sample consisted of a cross section of people including senior executives and managerial personnel from all the departments of the participating organizations. The sampling technique employed is convenience based non-probability sampling. According to Churchill (1979), this type of sampling can be adopted when the emphasis is on exploratory research. The researcher delivered the questionnaires to the organizations, in both the countries, personally and the completed questionnaires were collected from the respondents in the same manner. The respondents were assured of confidentiality and anonymity.

\section{Measures}

Transformational leadership was measured using a 28-item scale developed by Podsakoff et. al. (1990). This scale measures leadership orientation based on the dimensions of articulate vision, role model, foster goal acceptance, performance expectations, individual support, intellectual stimulation and transactional leader behavior. All items were rated on a 4-point scale with 1= "does not apply" and 4= "applies to a great extent."

Organizational culture was measured using OCTAPACE developed by Pareek (1973). The OCTAPACE profile is a 40-item instrument that gives the profile of organization's ethos in eight values (Openness, Confrontation, Trust, Authenticity, Proaction, Autonomy, Collaboration, Experimenting). The instrument contains two parts. In part one, values are stated in items 1 to 24 (three statements each of the eight values), and the respondents were required to check (on a 4-point scale ranging from 1= "not valued in the organization" to 4= "very highly valued in the organization"). Part two contains sixteen statements on beliefs, two each for eight values, and the respondent checks (on a 4-point scale ranging from $1=$ "few or no people in this organization share this belief" to 4= "this belief is well shared in this organization") how much each item is valued in her/his organization.

Learning Organization was measured using the Learning Organization Profile developed by Marquadt (1996). The profile is a 50-item instrument assessing five dimensions; learning dynamics, organization transformation, people empowerment, knowledge management, and technology application). All items were rated on a 4-point scale ranging from 1 (does not apply) to 4 (applies to a great extent).

\section{Data Analysis}

The hypotheses were tested using t-tests, correlational analysis and multiple regression analysis. To determine whether significant differences existed in the development of learning organization t-test was computed. In order to understand the relationship between the learning organization and the various dimensions of transformational leadership as well as organizational culture Pearson's Product Moment Correlation was computed. Regression is the determination of statistical relationship between two or more variables. Learning Organization was taken as the dependent or criterion variable and transformational leadership and organizational culture as the independent variables or predictor variables. Stepwise Multiple Regression was used.

\section{RESULTS}

\section{Preliminary Analysis}

First, a preliminary analysis was done with all of the survey items to test the scales' psychometric properties. Those items that demonstrated adequate reliability (Cronbach alphas of above .60) were retained. Based on this analysis 25 items were retained in the Learning Organization Profile. All the items were retained in the transformational leadership measure and OCTAPACE as these measures had adequate reliability. Intercorrelations also showed generally positive relationships. 


\section{Results and Findings}

T-test of difference was conducted between Nepal and India on all the dimensions of learning organization. The findings suggested that organizations in the pharmaceutical sector in India showed the existence of some subsystems of the learning organization (learning dynamics, organization transformation, and technology application) as compared to Nepal.

Transforming to learning organization involves incorporating the five subsystems of the learning organization: learning dynamics, organization transformation, people empowerment, knowledge management and technology application (Marquadt, 1996). Attempting to become a learning organization without all five of these dimensions will be insufficient. If any of the subsystem is weak or absent, the effectiveness of the other subsystems is significantly weakened. India showed significant differences only in the dimension of learning dynamics, organization transformation and technology application. Though organizations in India did understand the importance of learning, the transformation was incomplete as the other two subsystems, people empowerment and knowledge management, was not present. The organizations in the pharmaceutical sector in Nepal are yet to understand the importance of learning and make the transition to a learning organization.

Hypothesis 3 was partially supported as no difference was found in the dimension of people empowerment and knowledge management between Nepal and India.

The result of correlational analysis shows that in India all the dimensions of transformational leadership, except for role model, show a significant and positive correlation with the dimension of learning organization. The dimension of role model did not show any significant correlation. In Nepal, too all the dimensions showed significant and positive correlations except for the dimension of role model, which did not show any significant correlation. Hypothesis 1 was accepted. With respect to organizational culture, in both the countries, all the dimensions of organizational culture were significantly and positively related to learning organization. Except for the dimension of autonomy, that showed a negative but insignificant correlation in India whereas in Nepal it showed no significant correlation. Hypothesis 2 was also accepted.

To gain an insight into the relationships further between the independent and dependent variables and to identify the predictive relationships between the two sets of variables, if any, multiple regression analysis was done. There are two sets of equation. In the first set independent variables are the dimensions of transformational leadership. The dependent variable is the dimension of learning organization. Results indicate that in India foster acceptance of group goals accounted for $25.5 \%$ of the variance with a $\beta$-coefficient of .505 . An increase of $5.1 \%$ was observed when performance expectation entered in the equation taking the total variance to $30.9 \%$ with a $\beta$ coefficient of .254. None of the other variables entered in the equation due to low level of tolerance. In Nepal foster acceptance of goals accounted for $37.5 \%$ of the variance with $\beta$ coefficient of .613 . An increase of $12 \%$ was observed when individual consideration was entered in the equation taking the variance to $49.5 \%$ with a $\beta$ coefficient of .359. The other variables did not enter into the equation.

For the second set of equation, the independent variable is the dimension of organizational culture while the dependent variable is the dimension of learning organization. In India, it was observed openness accounted for $35.5 \%$ of the variance with a $\beta$ coefficient of .596 . An increase of $10.6 \%$ was observed when proaction entered in the equation with a $\beta$ coefficient of .344. Finally, authenticity accounted for an increase of $3.7 \%$ taking the total variance to $49.8 \%$ with a negative $\beta$ coefficient of .204 . None of the other variables entered the equation. In Nepal, openness accounted for $53.4 \%$ of the variance with a $\beta$ coefficient of .731 . An increase of $7.5 \%$ was observed when proaction entered in the equation taking the total variance to $60.9 \%$ with a $\beta$ coefficient of .355 . None of the other variables entered the equation.

\section{DISCUSSION AND CONCLUSIONS}

Transforming to learning organization has become an organizational imperative in the $21^{\text {st }}$ century. Prior research has suggested that transformational leadership and a generative and adaptive culture are one of the most 
important factors that influence the development of learning organization. Based on prior research two hypotheses were proposed to understand the relationship between transformational leadership and learning organization and also organizational culture and learning organization. A third hypothesis was proposed to investigate and compare if there existed any difference in the development of learning organization in Nepal and India.

Findings based on Nepalese and Indian organizations in the telecommunication sector provide support for the expectation that transformational leaders have a positive influence in the development of a learning organization; a generative and adaptive organizational culture also has a positive influence in the development of a learning organization. A difference was found in the development of learning organization in Nepal and India and it was observed that some of the subsystems were found to be present in the organizations in India. However, attempting to become learning organization without incorporating all five systems is insufficient. The Pharmaceutical sector in India does understand the importance of learning but the absence of two subsystems weakened the efforts. Though the pharmaceutical sector in Nepal is facing stiff competition, they do not focus on learning to improve performance. The focus is more on short-term gains rather than long-term growth and survival.

Findings also suggest that leaders in both the countries under study do not demonstrate transformational leadership characteristics. Though there is support for transformational leaders having a positive impact on the development of a learning organization, this could not be seen in both the countries under study. The reason for this could be the impact national culture has on the leadership style and influence tactics used by organizational leaders. The sample companies for the study were from Nepal and India where cultural values are relatively high in power distance. Pasa (2000) found in his study that leaders in cultures, which are high on collectivism and power distance value dimension, use the more directive forms of influencing tactics. The frequently perceived influence behaviors in such cultures are "granted power/authority", "taking over responsibility", "rationalizing and involving" and "pressure". The leaders use these influence behaviors to obtain obedience and compliance of followers. This is seen in the sample companies in both the countries where the leaders expected followers to comply rather than act on their own. This differs from the transformational leaders who create followers who are capable of handling challenges on their own. Since many aspects of leadership behavior can be learned the findings suggest that to facilitate the transition organizations should encourage managers to develop and display transformational leadership behaviors through training and mentoring processes.

Findings suggest that organizational culture in both the countries is not conducive to learning. In both the countries, openness and proaction contributed positively to predict learning organization. However, these are not the only cultural values that support and facilitate learning. Hence, the organizational culture cannot be considered as conducive to learning in both the countries. Though there is support in the literature that organizational culture has an important role to play in the development of a learning organization, the organizational culture of the sample companies in both the countries did not support learning. While this study did not examine the dual link between leadership and culture, there is support in the literature for this dual link. Leaders shape the culture of an organization and the organizational culture also influences the leadership style of individuals and teams (Ogbonna and Harris, 2000). Bass and Avolio (1993) suggest that transformational leaders help to develop a transformational culture and transformational cultures are necessary to create a flexible and adaptive culture, conducive to ongoing change and which promotes organizational learning. In both the countries under study, it is seen that the leaders do not demonstrate transformational leadership characteristics. As a result, they do not favor a generative and adaptive culture, which is supportive of learning among organizational members.

The current findings also have several limitations. Firstly, the sample size could be expanded, as data collected from a larger number of companies will permit more powerful hypothesis test. This study was based on self-report data and so the findings may be biased by common method variance and spurious cause/effect inferences. Common method variance is a potential problem whenever data are collected from a single source. Having a single respondent for each variable does not allow to test with-in group agreement. This could be an important issue because the extant literature has indicated that different followers/employees may have different perceptions about their superior's leadership style and organizational culture (Klein and House, 1995).

The generalizations occurring from this study are more conducive and limited to a particular group of employees who have been included in the study. In other words, the limitation comes from the sampling technique 
used, which is non-probability based convenience sampling. The major inherent drawback of this technique is that it does not provide the researcher with any kind of sound foundation for making general inferences about the population from which this sample is drawn.

This study has highlighted the importance of leadership and organizational culture. Besides these two factors, there are a number of other factors that influence the development of learning organization. A study of other factors would provide a fruitful insight into the development of learning organization. It would also be useful to study the interaction effect of transformational leadership and organizational culture and its impact on learning organization, which was not dealt with in this study.

\section{AUTHOR INFORMATION}

Sapna Rijal is senior lecturer of management at the Faculty of Management at Purbanchal University in Nepal. She received her Ph.D. in organizational behavior from the Faculty of Management Studies at University of Delhi. Her research interest includes learning organization, transformational leadership and organizational culture.

\section{REFERENCES}

1. Appelbaum, S.H., St-Pierre, N., \& Glavas, W. 1998. Strategic organizational change: the role of leadership, learning, motivation and productivity. Management Decision, 36(5): 289-301.

2. Barrett, F.J. 1995. Creating appreciative learning cultures. Organizational Dynamics, 24(1): 36-49.

3. Bass, B.M., \& Avolio, B.J. 1993. Transformational leadership and organizational culture. Public Administration Quarterly, 17(1): 112-121.

4. $\quad$ Bluedorn, A.C., \& Lundgren, E.E. 1993. A culture-match perspective for strategic change. Research in Organizational Change and Development, 7: 137-179.

5. Caudron, S. 1993. Change keeps TQM programs thriving. Personnel Journal, 72(10): 104-107.

6. Churchill, G.A. 1979. A paradigm for developing better measure of marketing constructs. Journal of Marketing Research, 16(1): 64-73.

7. Conger, J.A., \& Kanungo, R.N. 1987. Toward a behavioral theory of charismatic leadership in organizational settings. The Academy of Management Review, 12(4): 637-647.

8. Fiol, C. M., \& Lyles, M. A. 1985. Organizational learning. Academy of Management Review, 10(4): 803813.

9. Garvin, D.A. 1993. Building a learning organization. Harvard Business Review, 71(4): 78-91.

10. Hersey, P., Blanchard, K., \& Johnson, D. (2000) Management of organizational behavior: leading human resources. Upper Saddle River, NY: Prentice-Hall.

11. Hill, R. 1996. A measure of the learning organization. Industrial and Commercial Training, 28(1): 19-25.

12. Johnson, J.R. 1998. Embracing change: a leadership model for the learning organization. International Journal of Training and Development, 2(2): 141-150.

13. Johnson, J.R. 2002. Leading the learning organization: portrait of four leaders. Leadership and Organization Development Journal, 23(5): 241-249.

14. Jones, A.M., \& Hendry, C. 1994. The learning organization: adult learning and organizational transformation. British Journal of Management, 5(2): 153-162.

15. Klein, K.J. \& House, R.J. 1995. On Fire: Charismatic leadership and levels of analysis. Leadership Quarterly, 6: 183-198.

16. Kotter, J.P., \& Heskett, J.L. 1992. Corporate culture and performance. New York: Free Press.

17. LeBrasseur, R., Whissell, R., \& Ojha, A. 2002. Organizational learning, transformational leadership and implementation of continuous quality improvement in Canadian hospitals. Australian Journal of Management, 27(2): 141-162.

18. Marquardt, M. J. 1996. Building the learning organization: a systems approach to quantum improvement and global success. New York: McGraw-Hill.

19. McGill, M.E., Slocum, Jr. J.W., \& Lei. D. 1992. Management practices in learning organizations. Organizational Dynamics, 21(1): 5-17.

20. Ogbonna, E. \& Harris, L.C. 2000. Leadership style, organizational culture and performance: empirical evidence from UK companies. International Journal of Human Resource Management, 11(4): 766-788. 
21. Pareek, U. 1973. Training instrument for human resource development. New Delhi: McGraw Hill.

22. Parry, K.W., \& Proctor, S.B. 2000. The New Zealand leadership survey, 1999. Monograph of the Center for the Study of Leadership, Victoria University, Wellington.

23. Pasa, S.F. 2000. Leadership influence in high power distance and collectivistic culture. Leadership and Organization Development Journal, 21(8): 414-426.

24. Paton, R. A. \& McCalman, J. 2000. Change management: a guide to effective implementation. New Delhi: Sage Publications.

25. Podsakoff, P.M., MacKenzie, S.B., Moorman, R.H., \& Fetter, R. 1990. Transformational leader behaviors and their effects on followers' trust in leader, satisfaction, and organizational citizenship behaviors.

Leadership Quarterly, 1(2): 107-142.

26. Prewitt, V. 2003. Leadership development for learning organizations. Leadership and Organization Development Journal, 24(2): 58-61.

27. Sadler, P., 2003. Leadership. London: Kogan-Page.

28. Schein, E.H. 1983. The role of the founder in creating organizational culture. Organizational Dynamics, 12(1): 13-28.

29. Schien, E.H. 1996. Three cultures of management: the key to organizational learning. Sloan Management Review, 38(1): 9-20.

30. Senge, P. 1994. The fifth discipline: the art and practice of the learning organization. New York: Currency Doubleday.

31. Tichy, N.M. \& Ulrich, D.O. 1984. The leadership challenge-a call for the transformational leader. Sloan Management Review, 26(1): 59-68.

32. Waldman, D.A., Ramirez, G.G., House, R.J., \& Puranam, P. 2001. Does leadership matter? CEO leadership attributes and profitability under conditions of perceived environmental uncertainty. Academy of Management Journal, 44(1): 134-143. 


\section{NOTES}

